\title{
Makara Journal of Science
}

Volume 24

Issue 1 March

Article 5

$1-24-2020$

\section{Chemical Modification of Kola-Nut (Cola Nitida) Testa for Adsorption of Cu2+, Fe2+, Mg2+, Pb2, and Zn2+ from Aqueous Solution}

\author{
Nwafor Ogechi Slyvanus \\ Department of Pure and Industrial Chemistry, University of Port Harcourt, Port Harcourt 500272, Nigeria \\ Chukwu Uche John \\ Department of Pure and Industrial Chemistry, University of Port Harcourt, Port Harcourt 500272, Nigeria, \\ uche.chukwu@uniport.edu.ng \\ Horsfall Mike Jnr \\ Department of Pure and Industrial Chemistry, University of Port Harcourt, Port Harcourt 500272, Nigeria
}

Follow this and additional works at: https://scholarhub.ui.ac.id/science

\section{Recommended Citation}

Slyvanus, Nwafor Ogechi; John, Chukwu Uche; and Jnr, Horsfall Mike (2020) "Chemical Modification of Kola-Nut (Cola Nitida) Testa for Adsorption of Cu2+, Fe2+, Mg2+, Pb2, and Zn2+ from Aqueous Solution," Makara Journal of Science: Vol. 24 : Iss. 1 , Article 5.

DOI: 10.7454/mss.v24i1.11727

Available at: https://scholarhub.ui.ac.id/science/vol24/iss1/5

This Article is brought to you for free and open access by the Universitas Indonesia at UI Scholars Hub. It has been accepted for inclusion in Makara Journal of Science by an authorized editor of UI Scholars Hub. 
Chemical Modification of Kola-Nut (Cola Nitida) Testa for Adsorption of Cu2+, $\mathrm{Fe} 2+, \mathrm{Mg} 2+, \mathrm{Pb} 2$, and $\mathrm{Zn} 2+$ from Aqueous Solution

\section{Cover Page Footnote}

The authors are grateful to the Department of Pure and Industrial Chemistry, University of Port Harcourt for making their research laboratory accessible. 


\title{
Chemical Modification of Kola-Nut (Cola Nitida) Testa for Adsorption of $\mathrm{Cu}^{2+}$, $\mathrm{Fe}^{2+}, \mathrm{Mg}^{2+}, \mathrm{Pb}^{2}$, and $\mathrm{Zn}^{2+}$ from Aqueous Solution
}

\author{
Nwafor Ogechi Slyvanus, Chukwu Uche John*, and Horsfall Mike Jnr. \\ Department of Pure and Industrial Chemistry, University of Port Harcourt, Port Harcourt 500272, Nigeria \\ *E-mail: uche.chukwu@uniport.edu.ng
}

Received February 26, 2019 | Accepted January 27, 2020

\begin{abstract}
In this study, kola-nut testa samples were modified with $0.1 \mathrm{M}$ acetic acid and $0.1 \mathrm{M}$ EDTA at room temperature. The modified Kola-nut testa samples were then characterized with respect to their $\mathrm{pH}$ at point of zero charge, melting point, specific gravity, Fourier-transform infrared (FTIR) spectra, and solubility. The characterization results of the modified Kola-nut testa (MKT) revealed that it was sparingly soluble in water, ethanol, and acetone but insoluble in n-hexane. The MKT had a specific gravity of $0.992 \pm 0.020$ and exhibited various $\mathrm{pH}$ values of $4.50 \pm 0.50$ and $12.00 \pm 0.50$ at the point of zero charges. The FTIR spectra of the MKT indicated the presence of $-\mathrm{OH}$ and $-\mathrm{NH}$ groups at 3310.97 $\mathrm{cm}^{-1}$, alkyl groups at $2928.53 \mathrm{~cm}^{-1}$, and aromatic rings at $1612.27-1529.81 \mathrm{~cm}^{-1}$. The results of the adsorption studies at various time intervals indicated that MKT had the capacity to adsorb $\mathrm{Fe}^{2+}, \mathrm{Mg}^{2+}, \mathrm{Zn}^{2+}, \mathrm{Cu}^{2+}$, and $\mathrm{Pb}^{2+}$ as follows: $1.90 \pm 0.30 \mathrm{mg} / \mathrm{g}, 1.80 \pm 0.20 \mathrm{mg} / \mathrm{g}, 1.40 \pm 0.20 \mathrm{mg} / \mathrm{g}, 0.10 \pm 0.01 \mathrm{mg} / \mathrm{g}$, and $0.05 \pm 0.01 \mathrm{mg} / \mathrm{g}$, respectively. Thus, $\mathrm{Fe}^{2+}, \mathrm{Mg}^{2+}$, and $\mathrm{Zn}^{2+}$ were quantitatively removed from the aqueous solutions, whereas $\mathrm{Cu}^{2+}$ and $\mathrm{Pb}^{2+}$ were not. The adsorption of $\mathrm{Fe}^{2+}, \mathrm{Mg}^{2+}, \mathrm{Zn}^{2+}, \mathrm{Cu}^{2+}$, and $\mathrm{Pb}^{2+}$ by MKT from the aqueous medium was dependent on certain factors such as $\mathrm{pH}$, temperature, adsorbent dosage, contact time, and initial metal-ion concentration.
\end{abstract}

Keywords: modified kola-nut testa, agro waste, adsorption, heavy-metal ions, EDTA

\section{Introduction}

The utilization of agro-waste materials in the remediation of wastewaters containing heavy metals has generated a lot of interest from researchers because of the availability of these materials at no cost and their biodegradability [1]. Agro-wastes have been found to be effective in the treatment of effluents laden with heavy metals [2-3]. Agro-waste materials like tur-dal husks, tamarind husks, and Bengal gram husks could be used as adsorbents for the decontamination of effluents laden with $\mathrm{Hg}^{2+}, \mathrm{Fe}^{3+}, \mathrm{Ni}^{2+}$, and $\mathrm{Cr}^{6+3}$. Other researchers have utilized agro-waste materials in the adsorption of heavy metals from aqueous solution [4-7]. The versatility of agro-waste in water treatment processes has received equal attention [2].

However, the utilization of agro-waste materials for other purposes may have cost implications because some agricultural products generate relatively high volumes of agro-waste at the point of processing [1]. Examples of these produces include sugarcane, kola nuts, groundnuts, oranges, mangos, watermelons, grains, and blood and bones from slaughter houses. The cost implication, however, is minimal compared to the gain derived from the end use of the agro-waste material. For example, urban waste facilities in Nanyang, China supply over twenty thousand homes with biogas [8]. In other regions of the world, specifically the United States, some farmers convert their agro-wastes into biogas (methane) to generate all the fuel they need to run their farms in situ [9]. The entire process is cost-effective and the agro-waste generated can be endlessly recycled and reused, thereby greatly minimizing their environmental burden and associated health hazards. These applications of agrowastes greatly reduce the disease burden of pollutants in the environment.

Anthropogenic sources are largely responsible for the contamination of natural water supplies with heavy metals [5], and researchers have expressed grave concern about the consequences of heavy metals in the environment [4, 10-16]. Long-term exposure to heavy metals is known to be deleterious to human health [17]. The physical properties of heavy metals, i.e., good electrical conduction, strength, rich hue, durability, and good optical properties [18], have led to their presence in virtually all aspects of contemporary life [19]. To negate their impact on the environment, the need to remove them from wastewaters has gained much attention from both 'town and gown' communities 
around the world. The shortcomings of conventional methods in the removal of heavy metals from aqueous solution, including their non-biodegradability and high cost and energy requirements, necessitates research to identify low-cost biodegradable materials [20-21].

The use of rice husks [22], the barks of dead biomass [23], peanut testa $[6,24]$, onion skins $[7,25]$, and several other agro-waste materials ${ }^{26}$ have been reported in the removal of heavy metals from aqueous solutions. However, there is no documentation of reports on the use of kola-nut waste in the removal of heavy metals. In Southern Nigeria, the processing of kola nuts generates a tremendous amount of waste, which is indiscriminately discarded in the environment and constitutes a nuisance [27]. Were it to be fully harnessed, this "nuisance" could offer a potential solution to water pollution problems. Phytochemical analysis of the kola-nut reveals that it contains tannins, alkaloids, saponins, glycosides, volatile oils, and steroids [28], which provides a scientific basis for its various uses. According to numerous reports, the chemical modification of agrowaste can greatly enhance the sorption capacity for heavy metals in aqueous solutions $[6,7,23,25,29,30]$. Thus, in this work; we explore the potential of unmodified and chemically modified kola-nut testa in the adsorption of some heavy metals.

\section{Methods}

Sample preparation. In this experiment, we used analytical-grade reagents obtained from BDH. Fresh samples of kola nuts were obtained from the Omuma community in the state of Rivers, Nigeria and were properly identified at the University of Port Harcourt herbarium. The kola nuts were hulled and their testas were washed, sun-dried, and sieved to particles $63 \mu \mathrm{m}$ in size for subsequent treatment with acetic acid and EDTA.

Modification and characterization of kola-nut testa. The method reported by Abdullahi [31] was adopted with slight modification. We equilibrated $100 \mathrm{~g}$ of kolanut testa $(63-\mu \mathrm{m}$ particle size) with $0.1 \mathrm{M}$ acetic acid for 24 hours. The mixture was filtered after 24 hours and washed several times with deionized water. The residue was then oven dried at $100{ }^{\circ} \mathrm{C}$ for $3 \mathrm{~h}$ and further equilibrated with 0.1 M EDTA for 24 hours. Finally, the mixture was filtered, and the residue was sun-dried. The dried residue was kept in a clean plastic bag and labeled as modified kola-nut testa (MKT). The MKT was then characterized to determine its specific gravity, solubility, melting point, $\mathrm{pH}$ at point of zero charge, and infrared spectra.

The melting point, solubility, and specific gravity were determined using methods described in the literature. ${ }^{31 \text {, }}$

${ }^{32}$ The functional groups of MKT were determined using a table-top Alpha Fourier-transform infrared (FTIR) spectrophotometer (Brucker: 12028429). The $\mathrm{pH}$ was measured using a Hanna pH meter (Model H12211), and the $\mathrm{pH}$ at point of zero charge was determined according to the method described in the literature [3132].

Preparation of metal ion solutions. A concentration of $100 \mathrm{ppm}$ was prepared for each of the following metalion solutions $\left(\mathrm{Pb}^{2+}, \mathrm{Zn}^{2+}, \mathrm{Cu}^{2+}, \mathrm{Fe}^{2+}\right.$, and $\left.\mathrm{Mg}^{2+}\right)$ by determining the appropriate masses of their salts using a Radway Analytical Balance (Model AS220/C/2). The following amounts of metal salts were obtained: A $0.1598 \mathrm{~g}$ of $\mathrm{Pb}\left(\mathrm{NO}_{3}\right)_{2}, 0.3357 \mathrm{~g}$ of $\left(\mathrm{CH}_{3} \mathrm{COO}\right)_{2} \mathrm{Zn} .2 \mathrm{H}_{2} \mathrm{O}$, $0.3174 \mathrm{~g}$ of $\mathrm{CuSO}_{4} .5 \mathrm{H}_{2} \mathrm{O}, 0.6448 \mathrm{~g}$ of $\left(\mathrm{NH}_{4}\right)_{2} \mathrm{SO}_{4}$. Fe $\mathrm{O}_{4} .6 \mathrm{H}_{2} \mathrm{O}$, and $0.6905 \mathrm{~g}$ of $\mathrm{MgCl} .6 \mathrm{H}_{2} \mathrm{O}$. Each of these metal salts was dissolved in 1000-ml volumetric flasks with deionized water.

Adsorption studies. The capacity of MKT to adsorb the heavy-metal ions $\left(\mathrm{Pb}^{2+}, \mathrm{Zn}^{2+}, \mathrm{Cu}^{2+}, \mathrm{Fe}^{2+}\right.$ and $\left.\mathrm{Mg}^{2+}\right)$ from aqueous solution was investigated under different equilibrium conditions (temperature, $\mathrm{pH}$, contact time, initial metal-ion concentration, and adsorbent dose). Five (5) $\mathrm{ml}$ of each metal-ion stock solution was used to make up $50 \mathrm{ml}$ with deionized water in 250-ml Erlenmeyer flasks. The $\mathrm{pH}$ of each metal solution in the flasks (working solution) was set to 6.0 using appropriate buffer solutions.

To each metal solution, we added $0.2010 \mathrm{~g}$ of MKT and the mixtures were agitated for $2 \mathrm{~h}$ at room temperature. Then, we filtered the mixtures through Whatmann No. 13 filter paper and collected the filtrates in sterile plastic containers. The final metal-ion concentration in each filtrate was determined using a Buck Atomic Absorption Spectrophotometer (AAS, Model: 210/211 VGP). The capacity of MKT to adsorb each of the heavy metals from aqueous solution was then evaluated using Equation 1.

The effect of temperature on the adsorption of the heavy metals by MKT from aqueous solution was determined by varying the temperatures from $40-80^{\circ} \mathrm{C}$. Each metal salt solution (10 ppm) was prepared from its stock solution, to which $0.2010 \mathrm{~g}$ of MKT was added. The mixture was agitated several times and then transferred to a thermostat water bath pre-set to the respective temperature $\left(40-80{ }^{\circ} \mathrm{C}\right)$ for $10 \mathrm{~min}$. At 10-min intervals, the mixture at that particular temperature was removed from the water bath, agitated, and filtered through the Whatmann No. 13 filter paper. The filtrate was collected and the metal-ion concentration determined using the Buck AAS. The amount of heavy-metal ions adsorbed by MKT at each temperature was calculated using the following mass balance equation [34]:

$$
Q_{e}=\left[\frac{C o-C e}{m}\right] \times V
$$


where Qe is the amount of heavy-metal ions adsorbed, $(\mathrm{mg} / \mathrm{g}), \mathrm{Co}$ and $\mathrm{Ce}$ are respectively the initial and final equilibrium metal-ion concentrations ( $\mathrm{ppm}), \mathrm{m}$ is the mass of MKT $(\mathrm{g})$, and V is the volume of the metal-ion solution (L). The amount of heavy-metal ions adsorbed by MKT was also expressed in terms of the percentage removal, $\%$ R, which we calculated using Equation 2:

$$
\% R=\left[\frac{(C o-C f)}{C o}\right] \times 100
$$

where $\mathrm{Co}$ and $\mathrm{Cf}$ are the initial and final metal ion concentrations of the adsorbate in ppm, respectively [3537].

We also determined the effect of varying $\mathrm{pH}(2.0-10.0)$ on the adsorption of heavy metals by MKT, following a procedure similar to that described above. In addition, we studied the adsorption of the metal ions $\left(\mathrm{Pb}^{2+}, \mathrm{Cu}^{2+}\right.$, $\mathrm{Zn}^{2+}, \mathrm{Mg}^{2+}$ and $\mathrm{Fe}^{2+}$ ) by MKT for different contact-time intervals. To do so, we varied the contact time of the adsorbent (MKT) and adsorbate (metal-ion solution) from 20-100 min (i.e., $20 \mathrm{~min}, 40 \mathrm{~min}, 60 \mathrm{~min}, 80 \mathrm{~min}$, and $100 \mathrm{~min}$ ) at room temperature. Finally, we investigated the influence of the initial metal-ion concentration and adsorbent dose on the adsorption of heavy metals by MKT at room temperature. The equilibrium adsorption of the heavy metals by MKT under these conditions was evaluated using Equation 1, as described by other authors [32, 38]. The experiments were performed in triplicate to ensure accuracy and their average values are reported here.

\section{Results and Discussion}

Characterization of MKT. MKT was found to be sparingly soluble in water, ethanol, and acetone but insoluble in n-hexane. The specific gravity result obtained for MKT was $0.992 \pm 0.020$. These results indicate that MKT is relatively dense relative to water. The $\mathrm{pH}$ values at the point of zero charge were found to be $4.50 \pm$ 0.50 and $12.00 \pm 0.50$, as shown in Figure 1, which are the neutral charges (i.e., zero charge) at which MKT is expected to effectively adsorb metal ions from aqueous solution [24, 32-33]. The sum of the charges on the surface of MKT are neutral (net charge is zero) at these initial $\mathrm{pH}(\mathrm{pHi})$ values because at these points the $\Delta \mathrm{pH}$ is zero. Similar results have been reported in the literature [24, 32-33].

The complex nature of MKT became more evident in its IR spectrum (Figure 2). The sharp and broad absorption band at $3310.97 \mathrm{~cm}^{-1}$ can be attributed to the $-\mathrm{OH}$ and $\mathrm{N}-\mathrm{H}$ stretching modes of alcohols and amines [39]. The intense sharp peak at $1612.27 \mathrm{~cm}^{-1}$ is attributable to the $-\mathrm{C}=\mathrm{C}$ - bonds of aromatic rings [39]. The $\mathrm{C}-\mathrm{H}$ stretching mode of the alkyl groups $\left(\mathrm{CH}_{3}, \mathrm{C}_{2} \mathrm{H}_{5}, \mathrm{C}_{3} \mathrm{H}_{7}\right.$, etc. $)$ exhibited weak absorption at $2928.53 \mathrm{~cm}^{-1}$. MKT also exhibited different absorption bands at the finger print region (1600-800 $\mathrm{cm}^{-1}$ ) [39]. The absorption band at 1300$1150 \mathrm{~cm}^{-1}$ was probably due to the $\mathrm{C}-\mathrm{O}$ stretching modes of the acids (RCOOH), esters (RCOOR), or anhydrides (RCOOCOR') [39]. A strong out-of-plane bending vibration arose from the terminal alkenes $\mathrm{RCH}=\mathrm{CH}_{2}$ between $800-1000 \mathrm{~cm}^{-1}$ and the sharp band at $1100.17 \mathrm{~cm}^{-1}$ is due to secondary alcohols, ROH [39]. These MKT absorption frequencies differed slightly from the IR spectrum of unmodified kola-nut testa (UKT), which is shown in Figure 3.

The melting point of MKT was inconclusive because there was no change in physical state (i.e., from solid to liquid) during the melting-point investigation (the thermometer scale range was $0-360{ }^{\circ} \mathrm{C}$ ). The color of the MKT changed in the temperature range of $70-90{ }^{\circ} \mathrm{C}$ during the melting point investigation. In addition, the MKT contained different mixtures of substances that are rich in carbon, some of which are susceptible to thermal degradation and therefore difficult to melt in a mixture. The implication of this MKT behavior is that it contained a complex mixture of materials with different melting points and other properties (chemical and physical).

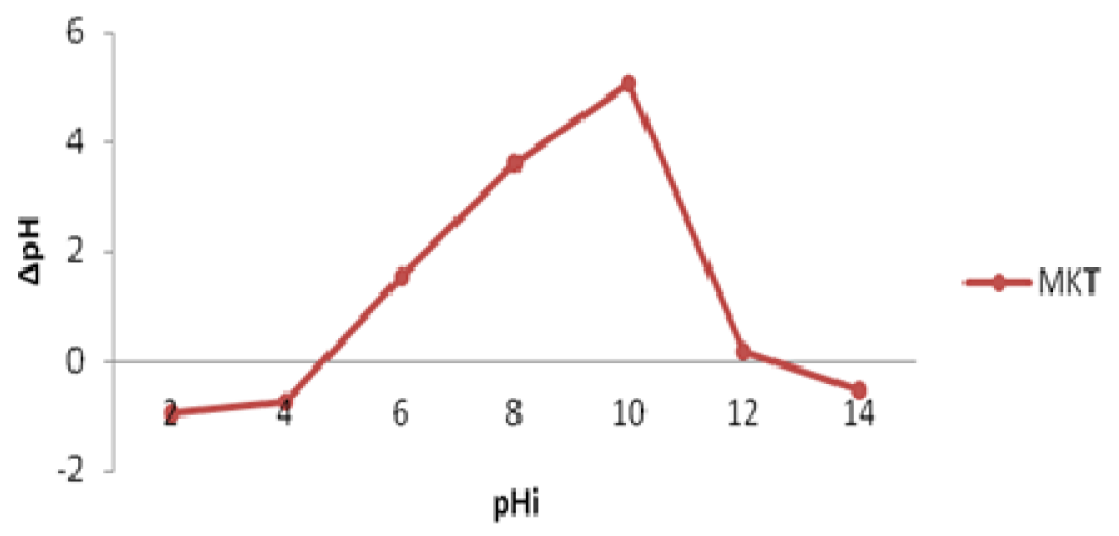

Figure 1. pH at Point of Zero Charge for MKT $(n=3)$ 

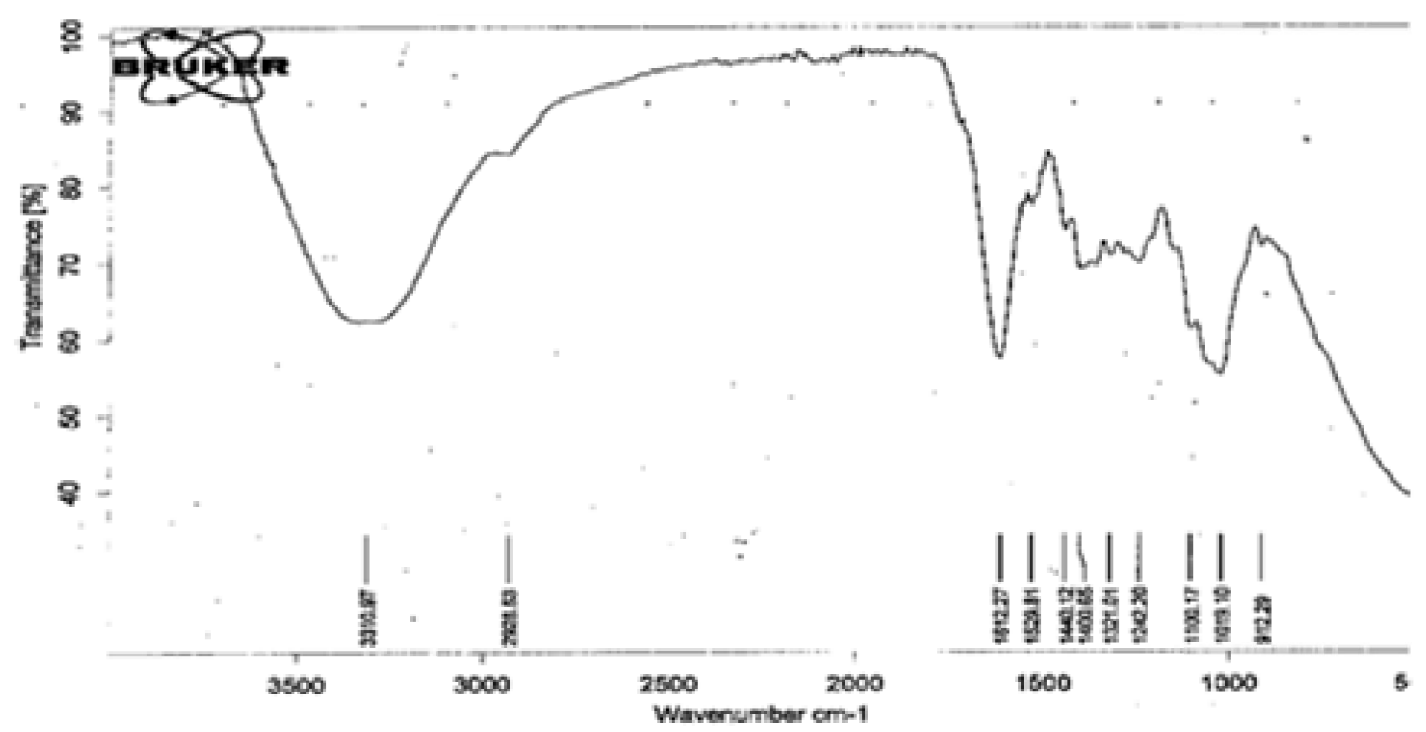

Figure 2. FTIR Spectrum of Modified Kola-nut Testa (MKT)

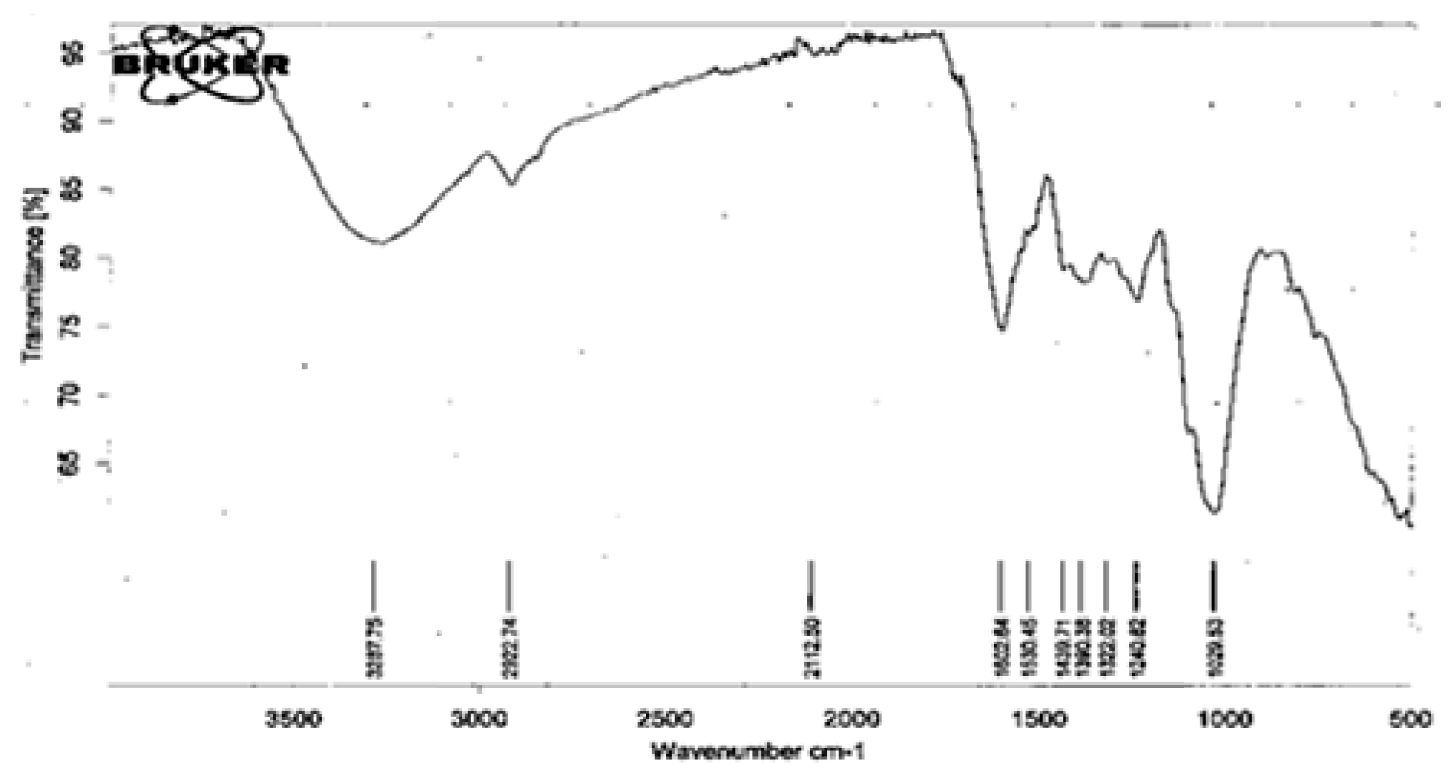

Figure 3. FTIR Spectrum of Unmodified Kola-nut Testa (UKT)

Adsorption of heavy metals. MKT was found to have the capacity to take up metal ions $\left(\mathrm{Pb}^{2+}, \mathrm{Cu}^{2+}, \mathrm{Zn}^{2+}\right.$, $\mathrm{Mg}^{2+}$, and $\mathrm{Fe}^{2+}$ ) from an aqueous medium. However, the amounts of copper and lead adsorbed were relatively poor. The highest adsorption capacity of MKT for each of the following metals, $\mathrm{Fe}^{2+}, \mathrm{Mg}^{2+}, \mathrm{Zn}^{2+}, \mathrm{Cu}^{2+}$ and $\mathrm{Pb}^{2+}$, at various contact-time intervals is as follows: 1.90 $\pm 0.30 \mathrm{mg} / \mathrm{g}, 1.80 \mathrm{mg} / \mathrm{g} \pm 0.20,1.40 \mathrm{mg} / \mathrm{g} \pm 0.20,0.10 \pm$ $0.01 \mathrm{mg} / \mathrm{g}$, and $0.05 \pm 0.01 \mathrm{mg} / \mathrm{g}$, respectively, as presented in Table 1.

The pertinent question to ask at this point is: why was MKT ineffective in adsorbing some heavy-metal ions from aqueous solution considering the fact that EDTA is a good complexing agent for the heaviest metal ions.
These deviations could be accounted for by reconsidering the chemical treatment and studying the nature of the heavy metals. It could be argued that the chemical treatment was not entirely successful due to stearic hindrances between the chelate (EDTA) and high-molecular-weight substances (bulky groups) likely present in the kola-nut testa. It is likely that only a limited fraction of EDTA was present in the MKT.

Secondly, the ligand (EDTA is a hexadentate ligand, i.e., it has six lone pairs of electrons that can fill the vacant orbitals in the metals) might have been associated with other groups present in the MKT through chemical interaction (hydrogen bonding, ionic or covalent interaction), thereby limiting the ability of 
MKT to effectively adsorb heavy metals from aqueous solution. To this end, relative success was recorded for the adsorption of $\mathrm{Zn}^{2+}, \mathrm{Mg}^{2+}$, and $\mathrm{Fe}^{2+}$, whereas the adsorption of $\mathrm{Cu}^{2+}$ and $\mathrm{Pb}^{2+}$ was very poor, as shown in Table 1. The poor adsorption of the metal ions $\mathrm{Cu}^{2+}$ and $\mathrm{Pb}^{2+}$ may be due to the bulky nature (size) of lead and copper, which may be difficult for MKT to adsorb because of the limited number of sites available for the adsorption of these metals. In summary, the increasing order of adsorption for the metal ions by MKT is as follows: $\mathrm{Pb}^{2+}<\mathrm{Cu}^{2+}<\mathrm{Zn}^{2+}<\mathrm{Mg}^{2+}<\mathrm{Fe}^{2}$.

Adsorption studies in different equilibration conditions. The results obtained regarding the adsorption of the metal ions $\left(\mathrm{Pb}^{2+}, \mathrm{Cu}^{2+}, \mathrm{Zn}^{2+}, \mathrm{Mg}^{2+}\right.$, and $\left.\mathrm{Fe}^{2+}\right)$ under different equilibrium conditions indicated that temperature influenced the adsorption of these heavy metals, as presented in Figure 4. An increase in temperature from $40{ }^{\circ} \mathrm{C}$ to $80{ }^{\circ} \mathrm{C}$ had little or no effect on the general percentage removal of the metal ions. $\mathrm{Fe}^{2+}$ recorded the highest percentage removal with an average of $73.56 \pm 0.6 \%$, followed closely by $\mathrm{Mg}^{2+}$ with $71.96 \pm 1.0 \%$ and $\mathrm{Zn}^{2+}$ with $46.20 \pm 0.4 \%$. For the metal ions $\mathrm{Cu}^{2+}$ and $\mathrm{Pb}^{2+}$, adsorption by MKT was very low (below $20.00 \%$ for $\mathrm{Cu}^{2+}$ and $3.00 \%$ for $\mathrm{Pb}^{2+}$ ). The results further revealed that each metal ion has a unique optimum temperature at which its adsorption from aqueous solution by MKT is favorable. The response of each metal-ion solution during interaction with the adsorbent (MKT) varied greatly, which is probably because the aqueous solution was a single-metal ion solution in which competition with other metal ions was minimal.

Table 1. Adsorption Capacities for Some Heavy-metal Ions by MKT at Room Temperature and Constant pH 6.0

\begin{tabular}{cc}
\hline Metal ion $\left(\mathbf{M}^{2+}\right)$ & $\begin{array}{c}\text { Adsorption capacity }(\mathbf{m g} / \mathbf{g}) \\
\text { Values for } M K T\end{array}$ \\
\hline $\mathrm{Pb}^{2+}$ & $0.05 \pm 0.01$ \\
$\mathrm{Cu}^{2+}$ & $0.10 \pm 0.01$ \\
$\mathrm{Zn}^{2+}$ & $1.40 \pm 0.20$ \\
$\mathrm{Mg}^{2+}$ & $1.80 \pm 0.20$ \\
$\mathrm{Fe}^{2+}$ & $1.90 \pm 0.30$ \\
\hline
\end{tabular}

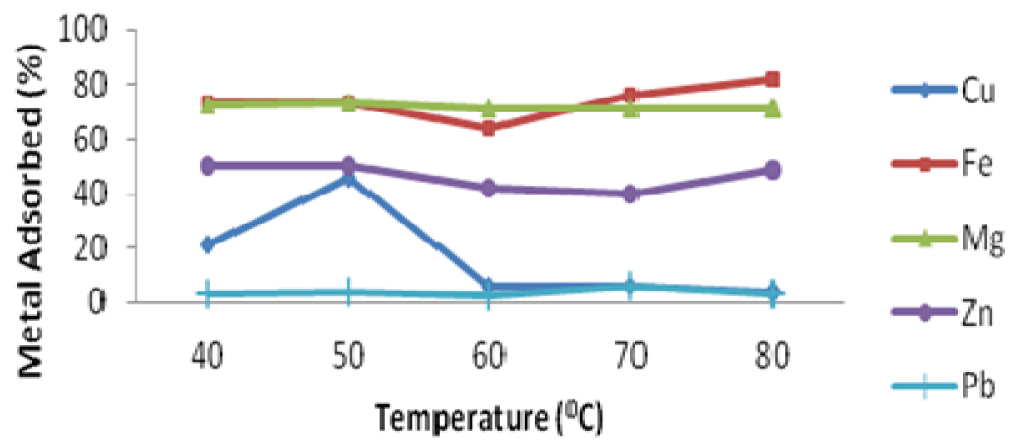

Figure 4. Effect of Temperature on the Percentage of Metal Adsorbed Using MKT at Constant pH 6.0

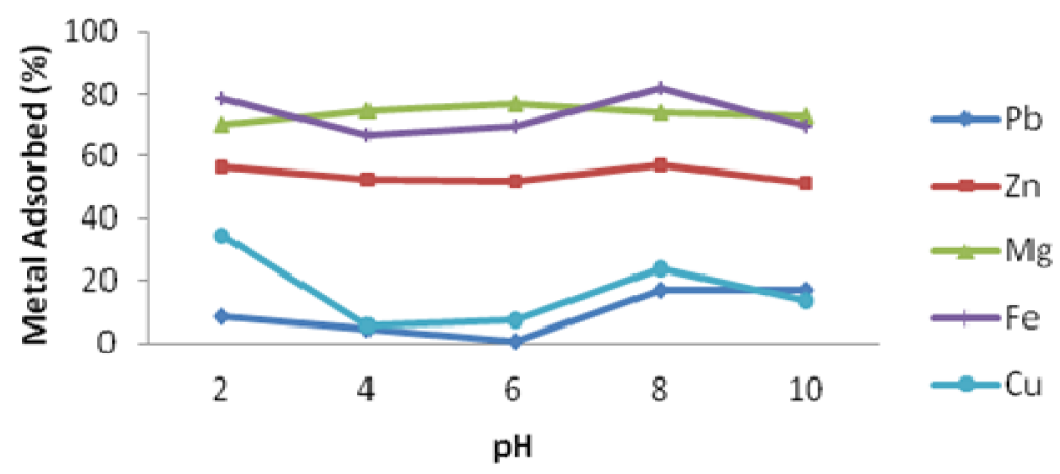

Figure 5. Effect of pH on the Percentage of Metal Adsorbed Using MKT at Room Temperature 


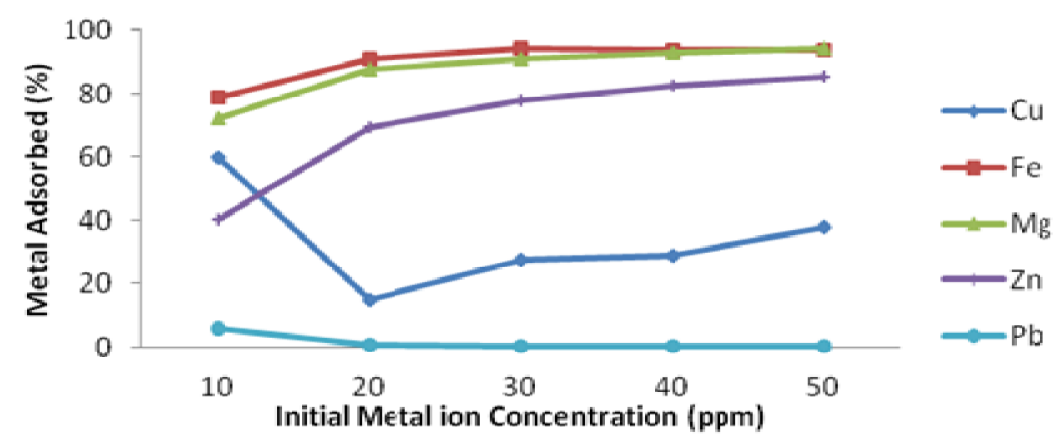

Figure 6. Effect of Initial Metal Ion on Percentage of Metal Adsorbed by MKT at Room Temperature and Constant pH of 6.0

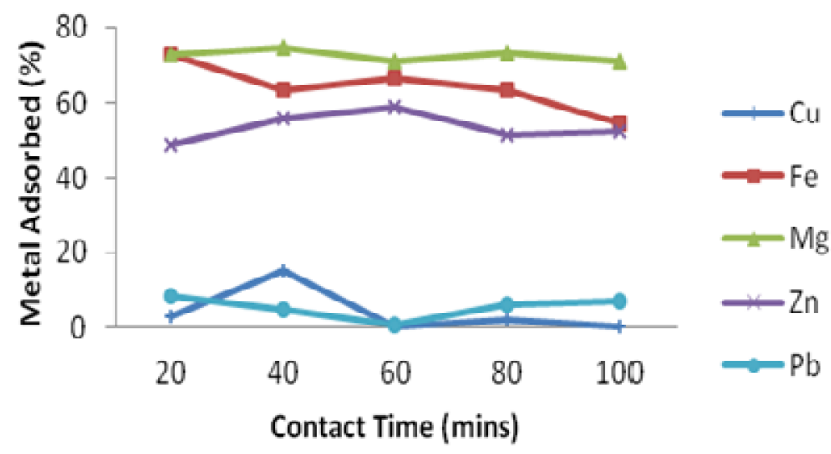

Figure 7. Effect of Contact Time on Percentage of Metal Adsorbed by MKT at Room Temperature and Constant pH of 6.0

$\mathrm{pH}$ has a profound effect on the extraction of heavymetal ions from aqueous solutions [40-41]. Figure 3 shows the results for the adsorption of the metal ions at different $\mathrm{pH}$ values (1.0-10.0). From the figure, we can see that $\mathrm{Fe}^{2+}$ had the highest percentage removal of $81.80 \%$ at $\mathrm{pH} 8.0$, closely followed by $\mathrm{Mg}^{2+}$ with $76.70 \%$ at $\mathrm{pH} 6.0$, and $\mathrm{Zn}^{2+}$ with $56.90 \%$ at $\mathrm{pH} 8.0$. Once again, the lead and copper ions were least adsorbed throughout the $\mathrm{pH}$ range of this study. Generally, their adsorption was slightly more favorable at $\mathrm{pH}$ 8.0. The values reported for the metal ions in the basic region suggest that precipitation of the metal ions as insoluble hydroxides $\mathrm{M}(\mathrm{OH})_{2}$ may have contributed to their extraction from the aqueous solution by other mechanisms, such as complexation, co-precipitation, or other routes [40-41]. The optimum $\mathrm{pH}$ for each metal ion differed considerably.

Figure 6 shows a graphical representation of the percentages of metal adsorbed at different metal ion concentrations by MKT. Increases in the metal-ion concentrations resulted in a corresponding increase in the percentages of metal ion adsorbed. Optimum values of $95.00 \%$ and $94.30 \%$ were recorded for $\mathrm{Fe}^{2+}$ and $\mathrm{Mg}^{2+}$, respectively, at $50 \mathrm{ppm}$ by MKT. These results were closely followed by $\mathrm{Zn}^{2+}$ with $85.2 \%$. Interestingly, at the very low concentration of $10 \mathrm{ppm}$, $\mathrm{Cu}^{2+}$ had an optimum adsorption value of $60.1 \%$, which subsequently dropped to $14.9 \%$ with further increases in concentration. The percentage removal of $\mathrm{Pb}^{2+}$ was abysmal, irrespective of the metal ion concentration.
The order of the percentage removal followed the same trend as above, with $\mathrm{Fe}^{2+}>\mathrm{Mg}^{2+}>\mathrm{Zn}^{2+}>\mathrm{Cu}^{2+}$ and $\mathrm{Pb}^{2+}$.

The percentages of metal adsorbed for different contact times (min) by MKT indicate that most of the $\mathrm{Fe}^{2+}$, $\mathrm{Mg}^{2+}$ and $\mathrm{Zn}^{2+}$ ions were adsorbed throughout the time of the study (20 $\mathrm{min}$ to $100 \mathrm{~min}$ ), as presented in Figure 7. $\mathrm{Mg}^{2+}$ recorded the highest average percentage of metal adsorbed $(72.58 \% \pm 1.20)$, followed by $\mathrm{Fe}^{2+}$ with an average of $63.82 \% \pm 0.80$ and $\mathrm{Zn}^{2+}$ with average of $53.50 \% \pm 1.00$. As usual, the amounts of copper and lead adsorbed by MKT were very low, which indicates that MKT is not an effective adsorbent for the removal of $\mathrm{Pb}^{2+}$ and $\mathrm{Cu}^{2+}$ ions from an aqueous medium. The adsorption capacity results of MKT for the metal ions presented in Table 1 above confirm this conclusion.

Finally, Figure 8 presents the percentage of metal adsorbed at different adsorbent doses (grams) by MKT. The dosages of the adsorbent ranged from $0.200 \mathrm{~g}$ to $1.000 \mathrm{~g}$. The percentage removal of magnesium (II) metal ions was highest, with an average value of $73.82 \% \pm 1.50$, followed by iron (II) metal ions with $75.16 \% \pm 2.55$ and zinc (II) metal ions with $46.99 \% \pm$ 2.32. As anticipated, the copper (II) and lead (II) metal ions gave very poor average percentage removal values of $30.34 \% \pm 2.74$ and $5.84 \% \pm 2.37$, respectively. In all, in this experiment, a small quantity of MKT was needed to adsorb the metal ions $\mathrm{Fe}^{2+}, \mathrm{Mg}^{2+}$, and $\mathrm{Zn}^{2+}$ from aqueous solutions, whereas $\mathrm{Pb}^{2+}$ and $\mathrm{Cu}^{2+}$ ions could not be efficiently removed by the adsorbent MKT. 


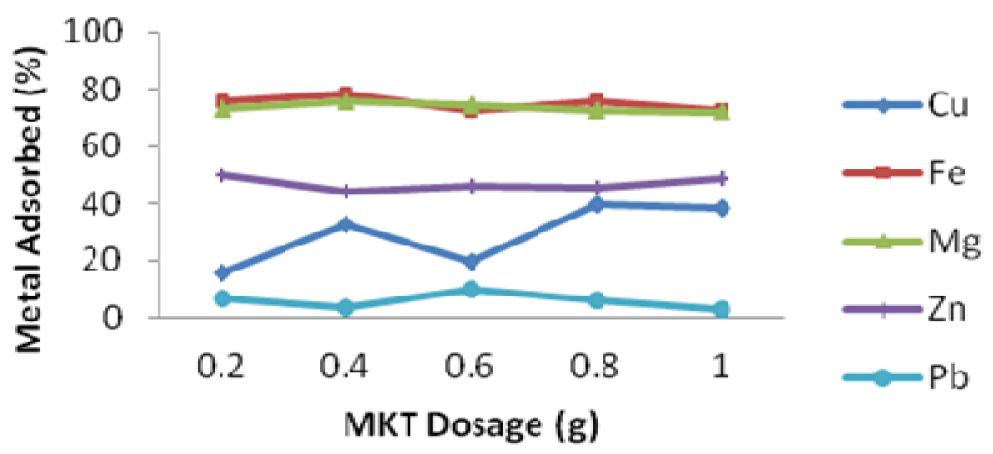

Figure 8. Effect of Adsorbent Dose (Grams) on Percentage of Metal Adsorbed by MKT at Room Temperature and Constant pH of 6.0

\section{Conclusion}

In this study, kola-nut testa modified with $0.1 \mathrm{M}$ acetic acid and 0.1 M EDTA (MKT) showed the capacity to remove certain heavy-metal ions $\left(\mathrm{Fe}^{2+}, \mathrm{Mg}^{2+}, \mathrm{Zn}^{2+}\right)$ from aqueous solution. The order of adsorption of the metal ions by MKT was as follows: $\mathrm{Pb}^{2+}<\mathrm{Cu}^{2+}<\mathrm{Zn}^{2+}<$ $\mathrm{Mg}^{2+}<\mathrm{Fe}^{2+}$. The highest adsorption capacity of MKT for each of the following metal ions, $\mathrm{Fe}^{2+}, \mathrm{Mg}^{2+}, \mathrm{Zn}^{2+}$, $\mathrm{Cu}^{2+}$, and $\mathrm{Pb}^{2+}$ at various contact-time intervals is as follows: $1.90 \pm 0.30 \mathrm{mg} / \mathrm{g}, 1.80 \mathrm{mg} / \mathrm{g} \pm 0.20,1.40 \mathrm{mg} / \mathrm{g}$ $\pm 0.20,0.10 \pm 0.01 \mathrm{mg} / \mathrm{g}$, and $0.05 \pm 0.01 \mathrm{mg} / \mathrm{g}$, respectively. However, MKT was not a good adsorbent for the removal of $\mathrm{Cu}^{2+}$ and $\mathrm{Pb}^{2+}$ from aqueous solutions. These findings showed that the application of $0.1 \mathrm{M}$ acetic acid and 0.1M EDTA in the modification of kola-nut testa for the adsorption of $\mathrm{Fe}^{2+}, \mathrm{Mg}^{2+}, \mathrm{Zn}^{2+}$ from wastewater is quantitatively effective. $\left(\mathrm{Fe}^{2+}\right.$ had the highest percentage removal of $81.80 \%$ at $\mathrm{pH} 8.0$, closely followed by $\mathrm{Mg}^{2+}$ with $76.70 \%$ at $\mathrm{pH} 6.0$ and $\mathrm{Zn}^{2+}$ with $56.90 \%$ at $\mathrm{pH} \quad 8.0$.). The chemical modification was relatively successful, thereby making MKT a viable option in the treatment of wastewaters containing the metal ions $\mathrm{Fe}^{2+}, \mathrm{Mg}^{2+}, \mathrm{Zn}^{2+}$.

\section{Acknowledgments}

The authors are grateful to the Department of Pure and Industrial Chemistry, University of Port Harcourt for making their research laboratory accessible.

\section{References}

[1] Akaranta, O. 2007. Agro Wastes Utilization: The Chemists Input. Inaugural Lecture Series of the University of Port Harcourt No. 55.

[2] Bhatnagar, A., Sillanpää, M., Witek-Krowiak, A. 2015. Agricultural Waste Peels as Versatile Biomass for Water Purification-A Review. Chem. Eng. J. 270: 244-271, https://doi.org/10.1016/j.cej.2015.01. 135.
[3] Chaturvedi, D., Sahu, O. 2014. Adsorption of Heavy Metals from Wastewaster. Glob. J. Environ. Sci. Technol. 2(3): 020-028.

[4] Salehzadeh, J. 2013. Removal of Heavy Metals $\mathrm{Pb}^{2+}, \mathrm{Cu}^{2+}, \mathrm{Zn}^{2+}, \mathrm{Cd}^{2+}, \mathrm{Ni}^{2+}, \mathrm{Co}^{2+}$ and $\mathrm{Fe}^{3+}$ from Aqueous Solutions by using Xanthium pensylvanicum. Leonardo J. Sci. 23: 97-104.

[5] Bandela, N.N., Babrekar, M.G., Jogdand, O.K., Geetanjali, K. 2016. Removal of Copper from Aqueous Solution using Local Agricultural Wastes as Low cost Adsorbent. J. Mater. Environ. Sci. 7(6): 1972-1978.

[6] Uchechukwu, T.O., Chukwu, U.J., Akaranta, O. 2016. Removal of Heavy Metal Ions in Produced Water Using Cation Exchange Resins from Formaldehyde Polymerized Peanut Testa (Arachis Hypogaea L.) Extract Catechins. IOSR J. Appl. Chem. 9(12): 35-41, https://doi.org/10.9790/57360912013541.

[7] Manizabayo, G., Chukwu, U.J., Abayeh, O.J. 2019. Extraction of Quercetin-Rich" Red Onion Skin with Acetone and Chemical Modification using Aromatic Diazonium Salts. Makara J. Sci. 23(2), https://doi.org/10.7454/mss.v23i2.11045.

[8] Tingting, L., Yufeng, W., Xi, T., Yu, G. 2015. Urban household solid waste generation and collection in Beijing, China. Resour. Conserv. Recycl. 104(A): 31-37, https://doi.org/10.1016/j.resconrec. 2015.09 .004$.

[9] Cunningham, P.W., Cunningham, M.A. 2004. Principles of Environmental science: Inquiry and Applications. McGraw-Hill Companies, Inc. New York.

[10] Srivastava, S., Goyal, P. 2010. Novel Biomaterials: Decontamination of Heavy Metals from Wastewater. Springer Publishing Inc. India.

[11] Opeolu, B.O., Bamgbose, O., Arowolo, T.A., Adetunji. M.T. 2010. Utilization of Biomaterials as Adsorbents for Heavy Metals' Removal from Aqueous Matrices. Sci. Res. Essays. 5(14): 17801787.

[12] Abia, A.A., Igwe, J.C. 2006. A Bioseparation Process for Removing Heavy Metals from Waste Wa- 
ter Using Biosorbents. Afr. J. Biotechnol. 5(12): 1167-1179.

[13] Järup, L. 2003. Hazards of Heavy Metal Contamination. Br. Med. Bul. 68(1): 167-182, https://doi.org/1 0.1093/bmb/ldg032.

[14] Mohan, D., Pittman Jr, C.V. 2007. Arsenic Removal from Water/Wastewater using Adsorbents-A Critical Review. J. Hazard. Mater. 142(1-2): 1-53, https://doi.org/10.1016/j.jhazmat.2007.01.006

[15] Fu, F., Wang, Q. 2011. Removal of Heavy Metal ions from Wastewaters: A Review. J. Environ. Manag. 92(3): 407-418. https://doi.org/10.1016/j.je nvman.2010.11.011.

[16] Ahalya, N., Ramachandra, T.V., Kanamadi, R.D. 2003. Biosorption of Heavy Metals. Res. J. Chem. Environ. 7(4): 10-15.

[17] Singh, R., Gautam, N., Mishra, A., Gupta, R. 2011. Heavy Metals and Living Systems: An Overview. Indian J. Pharm. 43(3): 246-253. https://doi.org/1 0.4103/0253-7613.81505.

[18] Jones, C.J. 2001. d- and f-Block Chemistry. Royal Society of Chemistry, Cambridge.

[19] Emsley, J. 2011. Nature's Building Blocks, New Edition, Oxford University Press, Oxford.

[20] Srivastava, S., Goyal, P. 2010. Novel Biomaterials: Decontamination of Heavy Metals from Wastewater. Springer. pp. 8-23

[21] Taamneh, Y. Sharadqah, S. 2016. The removal of Heavy metals from Aqueous Solutions using Natural Jordanian Zeolite. Springer. pp. 1-8.

[22] Hegazi, A.H. 2013. Removal of Heavy metals from Wastewater using Agricultural and Industrial Wastes as Adsorbents. HBRC J. 9(3): 276-282, https://doi.org/10.1016/j.hbrcj.2013.08.004.

[23] Bailey, E.S., Olin, T.J., Bricka, R.M. Adrian, D.D. 1999. A review of potentially Low-cost sorbents for Heavy metals. Water Res. 33(11): 2469-2479, https://doi.org/10.1016/S0043-1354(98)00475-8.

[24] Uchechukwu, T.O., Chukwu, U.J., Chukwu, Akaranta, O. 2018. Equilibrium Studies for the Removal of $\mathrm{Fe} 2+, \mathrm{Ni} 2+, \mathrm{Pb} 2+, \mathrm{Cu} 2+$ and $\mathrm{Zn} 2+$ in Wastewater on Formaldehyde Polymerized Peanut Test (Arachishypogaea L.) Extract. IOSR J. Appl. Chem. (IOSR-JAC). 11(3): 63-74, https://doi.org/1 0.9790/5736-1103016374.

[25] I. Orji, M.U. Ibezim-Ezeani, O. Akaranta. Utilization of Red onion skin extract for Remediation of Lead (II) and Candium (II) ions from aqueous solution. International Journal of Enhanced Research in Science, Technology and Engineering. 2016, 5(7): 283-291.

[26] D. Chaturvedi, O. Sahu. Adsorption of Heavy Metals from wastewaters. Global Journal of Environmental Science and Technology. 2014, 2(3): 20-28.

[27] Asogwa, E.U., Otuonye, H.A., Mokwunye, C.F., Oluyole, K.A., Ndubuaku, C.N.T., Uwagboe, O.E. 2011. Kolanut Production, Processing and Market- ing in the South-Eastern States of Nigeria. Afr. J. Plant Sci. 5(10): 547-551.

[28] Kanoma, I.A., Muauhammad, I., Muauhammad, S., Abdullahi, K., Shehu, H.M., Maishanu, A.D. Isah. Qualitative and quantitative phytochemical Screening of Cola Nuts (Cola nitida and Cola acuminate). Journal of Biology, Agriculture and Healthcare. 2014, 45(5):89-97.

[29] Sud, D., Mahajan, G., Kaur, M.P. 2008. Agricultural Waste Material as Potential for Sequestering Heavy Metal ions from Aqueous Solutions-A review. Bioresources Technol. 99(14): 6017-6027, https://doi.o rg/10.1016/j.biortech.2007.11.064.

[30] Bhatnagar, A., Sillanpaa, M., Witek-krowiak, A. 2015. Agricultural Waste peels as versatile Biomas for water Purification. A Review. Chem. Eng. J. 270: 244-271, https://doi.org/10.1016/j.cej.2015. 01.135 .

[31] Abdullahi, M., Nsi, E.W., Onoja, P.K. 2015. The use of unmodified EDTA and Oxalic acid modified Beans Husks as Hazardous Remediation agent. IOSR J. Environ. Sci. Toxicol. Food Toxicol. 9(6): 01-09.

[32] Uchechukwu, T.O. 2017. Cation Exchange Properties of Chemically Modified Peanut Testa (Arachishypogaeal) Extract for the Treatment of Waste Water. Ph.D Thesis submitted to Pure and Industrial Chemistry Department, University of Port Harcourt.

[33] Cardenas-Peña, M.A., Jorge, G.I., Ruben, V.M. 2012. Determination of the Point of Zero Charge for Electrocoagulation Precipitates from an Iron Anode. Int. J. Electrochem. Sci. 7: 6142-6153.

[34] Pal, R., Tewari, S., Jai. P.N. 2009. Metals sorption from aqueous solutions by Kluyveromyces marxianus: Process optimization, equilibrium modeling and chemical characterization. Biotechnol. J. 4(10): 1471-1478. https://doi.org/10.1002/biot. 200900051.

[35] Singha, S.A., Guleria, A. 2015. Utility of Chemically Modified Agricultural Waste Okra Biomass for Removal of Toxic Heavy Metal ions from Aqueous Solution. Eng Agric. Environ. Food. 8: 52-60. https://doi.org/10.1016/j.eaef.2014.08.001.

[36] Youssef, A.M., Dawy, B.M., Akland, A.M., AbouElanwar, M.A. 2013. EDTA Versus Nitric Acid Modified Activated Carbon for Adsorption Studies of Lead (II) from Aqueous Solutions. J. Appl. Sci. Res. 9(1): 897-912.

[37] Kumar, R., Sangeeta, O., Sharma, A. 2012. Biosorption of heavy metal ions by using modified waste tree bark materials. Int. J. Environ. Sci. 3(1): 720-726.

[38] Adediran, G.O., Tella, A.C., Mohammed, H.A. 2007. Adsorption of $\mathrm{Pb}, \mathrm{Cd}, \mathrm{Zn}, \mathrm{Cu}$ and $\mathrm{Hg}$ ions on Formaldehyde and Pyridine Modified Bean Husks. J. Appl. Sci. Environ. Manage. 11(2): 153-158, https://doi.org/10.4314/jasem.v11i2.55019. 
[39] Uzoukwu, B.A. 2009. Basic Analytical Chemistry Millennium Edition. Paragraphics, Port Harcourt, Nigeria. pp. 279-284.

[40] Horsfall, M. Jnr. 2014. Fundamental Principles of Analytical Chemistry. 1st Ed. Soteria Publishing House, Port Harcourt.
[41] Chukwu, U.J., Uzoukwu, B.A. 2012. Extraction of $\mathrm{Cu} 2+$ Ions from Aqueous Solutions of Bromide Ions using 1-Phenyl-3-Methyl-4-Trichloro acetylpyrazolone-5 and Molecular Modeling of the Complex. Recent Pat. Mater. Sci. 5(1): 1-6, https://doi.or g/10.2 174/1874465611205010068. 